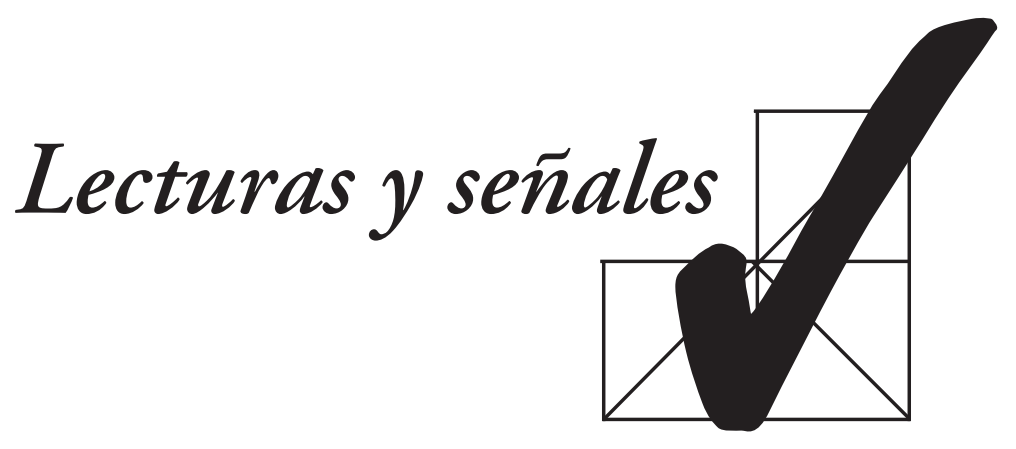

\title{
Construyendo los caminos del GIA. Un recorrido interdisciplinario por los Grupos Institucionales de Alcoholismo
}

\author{
Diana Kordon
}

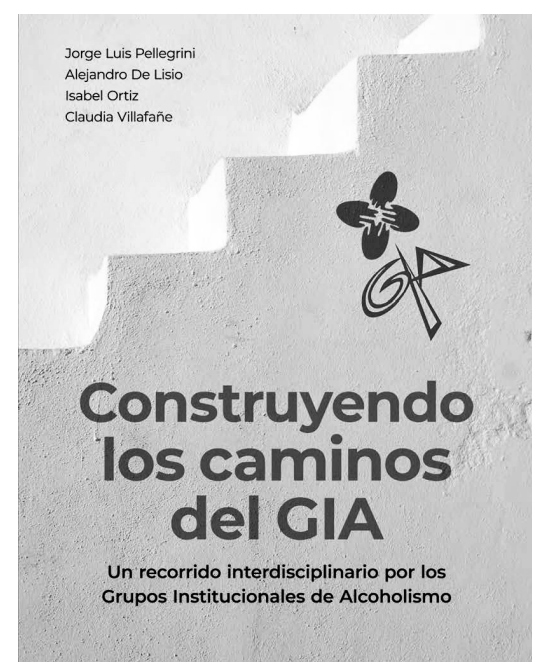

Jorge Luis Pellegrini, Alejandro De Lisio, Isabel del Carmen Ortiz, Claudia Inés Villafañe (Compil.) Carbono, 2019.

Dice Edgar Allan Poe en el hermoso cuento La carta robada, que algo puede ser ocultado poniéndolo tan evidencia que no se lo ve: "Lo que escapa a la observación por su excesiva evidencia". Con la problemática del alcoholismo ocurre algo así. Naturalizado al extremo, está incorporado a la vida cotidiana como un elemento más. Siendo quizás uno de los problemas psicosociales de mayor envergadura, que debería ser materia fundamental de políticas de Salud Pública, la cuestión del alcoholismo permanece negada.

En 1984 Jorge Pellegrini fundó los Grupos Institucionales de Alcoholismo (GIA), en el marco del Hospital Zonal de General Roca, en Río Negro y, luego de esa experiencia inicial, llevó la propuesta a cada rincón de nuestro país donde encontraba acogida en profesionales, técnicos y trabajadores interesados en comprometerse con el proyecto. Así se fue desplegando la Red GIA, que hoy tiene una amplia existencia real de carácter nacional y federal y que ha organizado sucesivos encuentros de sus miembros (ver la entrevista en la que lo relata en Vertex, 146, julio-agosto, 2019).

Este libro, de producción colectiva, recoge diferentes experiencias y conceptualizaciones a partir del desarrollo de una tarea comprometida en los GIA. Encontramos en él, sobre una matriz común, conceptual y empírica, además de la inserción en los hospitales públicos, que fue una premisa fundacional, la utilización de múltiples recursos para la tarea: trabajo interdisciplinario, inclusión en redes comunitarias y en las familias generando espacios de socialización, recuperación de las diferentes formas y contenidos del saber popular, promoción de inquietudes artísticas, etc.

Sobre la base de la concepción de los GIA formulada por Pellegrini, cada grupo fue siguiendo un camino de construcción propio de acuerdo a las características culturales, políticas y sociales de cada región y de acuerdo a la diversidad de obstáculos, resistencias y nuevos requerimientos que se le presentaban, haciendo específica la singularidad de cada experiencia. Como diría Pichon Rivière, tiene la riqueza de lo heterogéneo en una verdadera polifonía de voces. En los diversos capítulos de la obra participan profesionales con amplia experiencia en el tema, y también coordinadores más noveles en la tarea. También hay aportes de pacientes. Se presentan 
experiencias de muy distinta trayectoria. Algunas con alto grado de desarrollo, incluso redes regionales, y otras más puntuales. Esta cartografía compleja enriquece el libro y da cuenta de un proceso en pleno desarrollo. En la lectura se aprecia, también, un trabajo de historización. Se analizan los elementos de perdurabilidad desde los comienzos hasta el presente, y los cambios sujetos a las modificaciones producidas en la escena social. En la mayoría de los casos el trabajo con los GIA se despliega en el hospital público. En otros se hace en el marco de instituciones de la comunidad; pero en todos se trata de un dispositivo que intenta comprometer el ámbito de la salud pública y los recursos comunitarios.

Como señalan los autores, es fundamental el papel del Estado, por presencia o por ausencia, aunque el compromiso del Estado es diferente según las zonas.

En la tarea de los GIA, la pertenencia está al servicio de la recuperación y del reconocimiento de la identidad de todos y cada uno de los miembros del grupo. Si bien es un dispositivo pensado y desarrollado para el abordaje del alcoholismo, también es posible implementarlo para el abordaje de otras adicciones que, por su dimensión social, son hoy objeto de enorme preocupación.

El texto examina diferentes aspectos de la experiencia. Sus ejes temáticos son: A) Distintos aspectos de la tarea GIA: diversas experiencias GIA, el papel de los hospitales públicos, el por qué, para qué y el con quién de la tarea, el hacer con el cuerpo, el espacio, la escucha, la memoria, los territorios, diferencias entre zonas rurales, pueblos y ciudades, historia de los GIA, su relación con otros abordajes de las adicciones, la perspectiva desde la psicología social; B) Otros consumos problemáticos y el GIA (alcance de los GIA, policonsumo y dependencia con drogas); C) Procesos diagnósticos en los GIA; D) Capacitación y formación de recursos humanos; E) El rol de la familia en el alcoholismo y en el abordaje terapéutico, el abordaje de los vínculos con niños, niñas y adolescentes; F) GIA y Género (consulta de mujeres como pacientes y como acompañantes; G) Las recaídas; H) El GIA y los pacientes en contexto judicial; I) Evaluación de resultados, y J) Historias de vida.

La experiencia grupal es fundamento y está presente en todos los equipos sin excepción. Todos definen este dispositivo como un entramado que anuda formas de saber, relaciones de poder y prácticas de subjetivación. La instalación de un dispositivo nuevo implica un duro trabajo para vencer resistencias internas y externas. Como en todos los abordajes vinculares, en el grupo el tercero está presente. Se instala, en términos concretos, la posibilidad y el límite, que habilitan efectos de potencia frente a la omnipotencia paralizante. El trabajo en los GIA funciona como una herramienta de auto-rescate en una tarea realizada con otros, en un proceso colectivo. Por lo tanto se trata de acompañar y no de dirigir.

Es importante que todos, incluido el equipo coordinador, sostengan la esperanza en las capacidades del otro. Confiar que siempre hay un área sana de la personalidad en el cual anclarse y fijar un punto de referencia vital. En este sentido se desprende de todos los aportes la idea de que no hay un polo de salud representado por los coordinadores y un polo de enfermedad colocado en los pacientes. Se evita una polaridad que no recuperaría los aspectos sanos de los pacientes y promovería una idealización omnipotente de los coordinadores. El encuadre, entendido como el conjunto de normas, el sistema de reglas que regulan el funcionamiento, las relaciones y el vínculo con la tarea, es fundamental para los GIA en todas las instancias de sus actividades, intra e interinstitucionales. Todos los autores señalan su importancia. Hora, día, coordinador. Ante la vulnerabilidad, ante la devastación psíquica, el encuadre otorga estabilidad, referencia, confianza. Como en otras problemáticas, el involucramiento de la familia es fundamental en el proceso de recuperación y en su sostenimiento. Por eso participan en los grupos. La visita domiciliaria es otro recurso que pone en juego la colaboración de la familia. Una especificidad es el abordaje de la problemática de niños y adolescentes que viven en un medio familiar donde la alcoholización atraviesa la vida cotidiana y un tema no menor son las vicisitudes de la abstinencia. Se aborda también la cuestión de las recaídas y el sentimiento de soledad, enfatizando que las mismas no implican un fracaso frente a la adicción: dado que la vida es conflicto, se trabaja en reconocer que no hay un "para siempre". Por ello no hay sano ni enfermo "para siempre", y en todo sujeto hay recursos de salud 